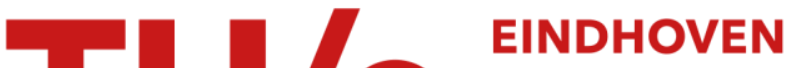 UNIVERSITY OF TECHNOLOGY
}

\section{Systematic design of multivariable fuel injection controllers for advanced diesel combustion}

\section{Citation for published version (APA):}

Luo, X., Donkers, M. C. F., de Jager, B., \& Willems, F. P. T. (2019). Systematic design of multivariable fuel injection controllers for advanced diesel combustion. IEEE Transactions on Control Systems Technology, 27(5), 1979-1990. https://doi.org/10.1109/TCST.2018.2842220

DOI:

10.1109/TCST.2018.2842220

Document status and date:

Published: 01/09/2019

\section{Document Version:}

Accepted manuscript including changes made at the peer-review stage

\section{Please check the document version of this publication:}

- A submitted manuscript is the version of the article upon submission and before peer-review. There can be important differences between the submitted version and the official published version of record. People interested in the research are advised to contact the author for the final version of the publication, or visit the $\mathrm{DOI}$ to the publisher's website.

- The final author version and the galley proof are versions of the publication after peer review.

- The final published version features the final layout of the paper including the volume, issue and page numbers.

Link to publication

\section{General rights}

Copyright and moral rights for the publications made accessible in the public portal are retained by the authors and/or other copyright owners and it is a condition of accessing publications that users recognise and abide by the legal requirements associated with these rights.

- Users may download and print one copy of any publication from the public portal for the purpose of private study or research.

- You may not further distribute the material or use it for any profit-making activity or commercial gain

- You may freely distribute the URL identifying the publication in the public portal.

If the publication is distributed under the terms of Article $25 \mathrm{fa}$ of the Dutch Copyright Act, indicated by the "Taverne" license above, please follow below link for the End User Agreement:

www.tue.nl/taverne

Take down policy

If you believe that this document breaches copyright please contact us at:

openaccess@tue.nl

providing details and we will investigate your claim. 


\title{
Systematic Design of Multivariable Fuel Injection Controllers for Advanced Diesel Combustion
}

\author{
Xi Luo, M.C.F. (Tijs) Donkers, Bram de Jager and Frank Willems
}

\begin{abstract}
With multiple fuel injections per combustion cycle, the advanced diesel combustion process depends on all injection pulses in a coupled way. This makes the control of the multi-pulse fuel injection profile challenging and the currently employed decoupled design methods might fail to guarantee closed-loop stability. Without explicit consideration of disturbances, it is also difficult for current design methods to guarantee the robustness of a fuel injection controller. In this paper, we present a general framework that describes the cycle-to-cycle fuel injection control problem. A control-oriented model is introduced and locally validated with experimental data. It considers disturbances and captures the coupled relation between the multi-pulse fuel injection profile and the combustion process. Based on the general framework and the control-oriented combustion model, we propose a systematic design approach to synthesize a multivariable fuel injection controller. With guaranteed robust stability and fast settling time ( 0.5 second / 5 combustion cycles in experiments), the controller's reference tracking performance and disturbance rejection capability are demonstrated experimentally on a singlecylinder engine test bench.
\end{abstract}

\section{INTRODUCTION}

$\mathbf{I}$ $\mathrm{N}$ advanced diesel combustion, the use of multi-pulse fuel injection leads to a larger flexibility in shaping the fueling profile. This enables lower engine-out emissions [1], such as nitrogen oxides (NOx) and particulate matter (PM). However, degradation in combustion performance may occur due to disturbances, such as changing intake conditions [2], different fuel properties [3], [4] and injector wear [5]. Closed-loop combustion control can be applied to keep the desired emission level and fuel economy in the presence of disturbances. Besides controlling the air-path [6], i.e., using the exhaust gas recirculation (EGR) rate and variable turbine geometry (VTG), the desired combustion performance can be recovered by controlling the fueling profile based on the cylinder pressure signal [7]. Closed-loop fuel injection control is also beneficial in reducing emission peaks in fast transient maneuvers [8]. This is because the variation of the fuel injection profile has an instantaneous impact on the combustion process, while the change of air-path conditions is generally too slow to influence the transient engine behavior. When closely spaced small injection quantities are requested, fuel injector variability becomes a key component to the cylinder-to-cylinder variation.

X. Luo, B. de Jager and F. Willems are with the Department of Mechanical Engineering, Eindhoven University of Technology, Eindhoven, The Netherlands (e-mail: \{X.Luo, A.G.de.Jager, F.P.T.Willems $\} @$ tue.nl).

M.C.F. (Tijs) Donkers is with the Department of Electric Engineering, Eindhoven University of Technology, Eindhoven, The Netherlands (e-mail: M.C.F.Donkers@tue.nl).

F. Willems is also with TNO Automotive, Powertrains Department, Helmond, The Netherlands (e-mail: Frank.Willems@tno.nl).
Closed-loop fuel injection control reduces the calibration effort by automatically manipulating the fuel injection profile. This helps to achieve more precise fueling profiles, which leads to balanced combustion process among multiple cylinders [9].

Cycle-to-cycle fuel injection control is practically feasible and has been extensively studied [4], [9]-[12]. Combustion metrics that are computed based on the cylinder pressure signal are commonly used as feedback signals, e.g., the indicated mean effective pressure (IMEP), the crank angle degree where $50 \%$ of the total accumulated heat release is reached (CA50) and the center of combustion (COC) which is defined as the peak location(s) of the rate of heat release (ROHR) curve. The fuel injection control problem is straightforward when there is only one injection pulse in each combustion cycle. In this case, a decoupled control scheme can be applied, in which the fuel injection timing and amount are controlled using two singleinput single-out (SISO) controllers based on CA50 and IMEP, respectively, see, e.g., [4], [10]. Since the coupling between these two feedback loops is weak, the use of this approach is justified and these two controllers can be designed independently. The control problem becomes challenging when having multiple injection pulses in one combustion cycle. This is due to the fact that, in this case, there are multiple combustion events in one cycle, where the latter combustion events are influenced by the previous ones. A decoupled fuel injection control scheme results in unsatisfactory dynamic performance with coupled tracking behavior [9], long settling time [11] and overshoot [12]. Therefore, it is desired to apply a multivariable (coupled) control scheme in advanced diesel combustion with multi-pulse fuel injection.

Methods for analyzing closed-loop stability and reference tracking performance of a fuel injection controller in advanced combustion with multi-pulse fuel injection do, to the best of the authors' knowledge, currently not exist in the literature. In this paper, we contribute to the design of the cylinder pressurebased cycle-to-cycle fuel injection controller by

1) presenting a general framework for closed-loop, cycleto-cycle fuel injection control;

2) introducing a control-oriented combustion model that considers disturbances, e.g., deviated intake conditions, as well as the coupled impact of changing the multipulse fuel injection profile on the combustion process;

3) analyzing the closed-loop stability, dynamical performance and robustness of a fuel injection controller;

4) providing a systematic design approach for a robust multivariable fuel injection controller with explicit consideration of disturbed conditions as well as guaranteed closed-loop stability and dynamical performance; 
5) experimentally demonstrating a multivariable fuel injection controller in both the nominal and the disturbed operating condition with deviated intake conditions.

The outline of this paper is as follows. The general closed-loop fuel injection control framework is discussed in Section II. Section III presents a control-oriented combustion model with an experimental validation. Section IV discusses the closedloop stability and the dynamical performance of a fuel injection controller. It also includes a systematic design method of a robust and multivariable fuel injection controller. Following the design method, a multivariable fuel injection controller is experimentally tested and discussed in Section V. Conclusions and directions for future research are stated in Section VI.

\section{GENERAL FUEL INJECTION CONTROL FRAMEWORK}

A general framework is needed to describe the fuel injection control problem with a multi-pulse fuel injection profile, which enables systematic solutions and benchmarking among different approaches. The actuators for combustion control include EGR and VTG for the air-path, and fuel injector for the fuel-path. Although both paths have significant influence on the combustion process, they have different time scales [6], [13]. The effect of changing the fueling profile can be seen within a few combustion cycles, while it is difficult to change the intake condition on a cycle-to-cycle basis by modifying EGR and VTG [14]. This clear separation of the fast and slow dynamics motivates the use of a cascade structure for controlling the entire combustion process. A fast fuel injection controller regulates the fueling profile on a cycle-to-cycle basis and considers the air-path to be quasistatic, while a slow airpath controller manipulates the intake conditions and considers the fuel-path to be infinitely fast. Since the focus of this paper is the design and analysis of a fuel injection controller, the air-path controller is not discussed further.

\section{A. Input and output signals}

With on/off control of the injector's needle lift, fuel is injected in pulses, such that the multi-pulse fueling profile can be parametrized with the injection timing and duration of each pulse. The executed injection profile may differ from the intended one, which is mainly due to fuel's hydraulic dynamics. Assuming these differences are repetitive from cycle to cycle, it is considered as part of the system behavior for the fuel injection controller. When accurate fuel injection profiles can be achieved by actively measuring the injected fuel amount, see, e.g., [5], fuel injector's dynamical behavior can be excluded and injection parameters can be defined as the actual injection timing and duration of each pulse. With $m \in \mathbb{N}$ pulses in one combustion cycle, the injection parameter $u \in \mathbb{R}^{2 m}$ for each fuel injector is defined as

$$
u=\left[\mathrm{SOI}_{1}, \mathrm{DOI}_{1}, \ldots, \mathrm{SOI}_{i}, \mathrm{DOI}_{i}, \ldots, \mathrm{SOI}_{m}, \mathrm{DOI}_{m}\right]^{\top},
$$

where $i=1 \ldots m$, and $\mathrm{SOI}_{i}$ and $\mathrm{DOI}_{i}$ are the (intended) start and duration of the $i$-th injection pulse, respectively. By considering the engine rotation speed, this general parametrization can be used to consider fuel injector's capabilities, i.e., avoid overlapped injection pulses. When a injection rate-shaping technique is used, see, e.g., [15], the injection parameters can be defined according to the geometric characteristics of the fueling profile.

Various types of engine performance can be considered as the outputs in the control problem. Generally, the engine performance $z \in \mathbb{R}^{q}$ is defined as

$$
z=[\tau, \eta, E]^{\top}
$$

where $\tau$ is the brake torque output, $\eta$ denotes the net indicated thermal efficiency and $E$ is the emission level of the engine-out pollutants, e.g., NOx, smoke, etc. Other engine performance elements can also be considered in $z$ if necessary, e.g., the exhaust gas temperature when the conversion efficiency of the after-treatment system is considered.

\section{B. Feedback signal}

Preferably, the engine performance is directly measured for closed-loop fuel injection control. However, this is considered difficult due to the lack of direct and fast on-board (emission) sensors. Due to insufficient accuracy and high computational complexity, estimated engine performance, i.e., engine-out emissions [16], is not currently used as the feedback signal in the cycle-to-cycle fuel injection control. Instead, combustion metrics, i.e., IMEP, CA50 and COC, are commonly used, which are denoted as $x \in \mathbb{R}^{n}$ with $n \in \mathbb{N}$. Based on the cylinder pressure and crank angle measurements, these combustion metrics are computed in real-time for each combustion cycle and show good correlation with the engine performance [17]. Hence, it is feasible and commonly accepted to control the combustion process using these combustion metrics [4], [9]-[12].

There are two widely accepted choices for feedback signals. One common choice is to use IMEP and combustion phase metrics, such as CA30, CA50, etc. As IMEP indicates the torque that is produced by a combustion cycle, it does not show the contributions of individual fuel injection pulses. Depending on the total amount of heat release, the changes of combustion phase metrics often become correlated when having multiple injection pulses. This leads to coupled feedback signals. Alternatively, one could consider the split contribution of IMEP and $\mathrm{COC}$ that correspond to each fuel injection pulse, which leads to fewer coupled feedback signals [9]. This approach is feasible based on the assumption that each injection pulse results in a separate combustion event, which often does not hold when having short or closely-spaced pilot injection pulses. In addition, the IMEP contribution of each injection pulse is not fully decoupled, since the starting moment of the next injection is assumed to be the end of the previous combustion event. As we aim to propose a systematic controller design method, both approaches can be considered in the general framework. The actual choice of feedback signals varies in each practical problem due to different objectives. Since decoupled feedback signals are not required when designing a multivariable fuel injection controller, we adopt the first choice due to its larger application scope, where the feedback signals include IMEP, CA30, CA50, etc. 


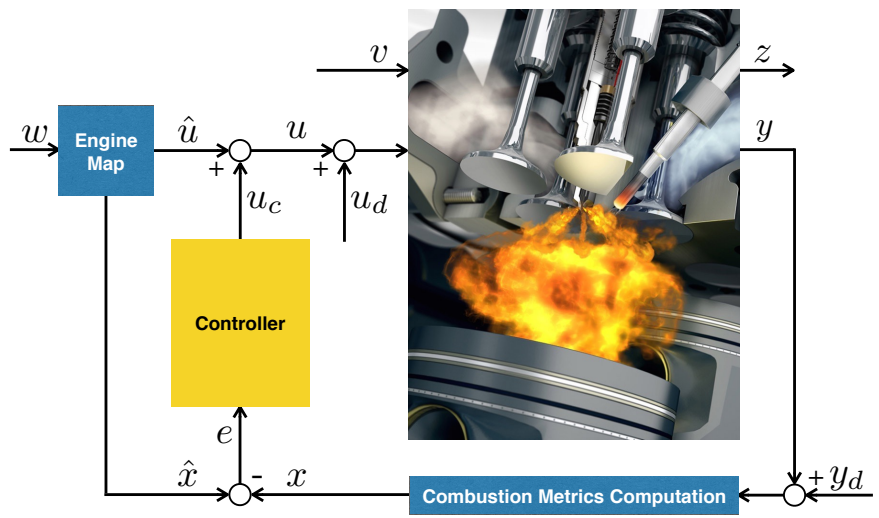

Fig. 1. Block diagram of cylinder pressure-based fuel injection control.

\section{Cycle-to-cycle fuel injection control scheme}

The block diagram of the fuel injection control scheme for a single cylinder is shown in Fig. 1. A parallel configuration based on this scheme can be considered for a multicylinder engine. In an operating condition $w$ with a certain torque request and engine rotation speed, the fuel injection set-points $\hat{u}$ are provided by the engine map. Although it leads to desired engine performance in nominal conditions, disturbances can cause undesired performance degradation with open-loop control. Disturbances include the injection profile deterioration denoted by $u_{d} \in \mathbb{R}^{2 m}$, which results from a possible mechanical or hydraulic malfunction of a fuel injector. Reduced engine performance may also result from deviated intake conditions, e.g., changed EGR ratio and airfuel ratio $(\lambda)$, which are caused by the disturbances of the air-path actuations $v \in \mathbb{R}^{p}$.

With closed-loop fuel injection control, the combustion metrics $x$ are used as the feedback signal, which are computed using measured cylinder pressure and crank angle signal $y$ subject to possible measurement noise $y_{d}$. Provided by either engine calibration or model-based optimization, the set-points for combustion metrics $\hat{x}$ are assumed to be known a priori, which leads to the desired engine performance. Based on the error signal $e \triangleq \hat{x}-x$, the controller computes $u_{c}$, such that fuel injection parameters that are assigned to a injector become $u=\hat{u}+u_{c}$. As desired engine performance is achieved when $e$ is close to zero, a well designed fuel injection controller computes $u_{c}$, such that the reference combustion metrics are quickly tracked with small steady-state variance. Since $z$ is not considered as the feedback, the optimality of the closed-loop controlled combustion performance depends on the choice of $\hat{x}$. With different choices of $u, x$ and $z$, existing fuel injection control schemes [4], [9]-[12] share the same controller design objective and fit in the block diagram as shown in Fig. 1.

\section{Cycle-to-cycle fuel injection controller}

A cycle-to-cycle fuel injection controller modifies the fueling profile on a cyclic basis. Due to the fast sample rate and the limited on-board computation power, a Proportional-Integral (PI) controller is commonly applied. With the combustion cycle index defined as $k \in \mathbb{N}$, the injection parameter assigned to one fuel injector in the $k$-th cycle is denoted by $u_{k}$ and the control output is $u_{c, k}$ with $u_{c, 0}=0$. The cycle-to-cycle control algorithm expressed with the cycle index is

$$
u_{c, k+1}=K_{p} e_{k}+K_{i} \sum_{i=0}^{k} e_{i},
$$

where $K_{p}$ and $K_{i} \in \mathbb{R}^{2 m \times n}$ are the gains of a multivariable PI controller. Instead using time, we label the discrete control input and tracking error with combustion cycle index $k$. Since we measure $e_{k}$ and compute $u_{k+1}$ in between consecutive combustion cycles $k$ and $k+1$, we have an extra cycle difference in (3), which is different from a traditional feedback controller [18, p. 66].

Categorized by the controller structure, two types of schemes are applied in closed-loop fuel injection control. First, a decoupled scheme containing multiple single-input singleoutput (SISO) controllers, which leads to diagonally structured $K_{p}$ and $K_{i}$, i.e., [4], [9]-[11]. Second, a coupled scheme containing a multi-input multi-output (MIMO) controller, such that $K_{p}$ and $K_{i}$ contain non-zero off-diagonal entries, see [12]. We regard controllers of these two schemes as the parallel fuel injection controller and the multivariable fuel injection controller, respectively.

\section{CONTROL-ORIENTED MODELING}

Having multiple fuel injection pulses in one combustion cycle, the fuel injection control problem becomes complex as the impact of changing each individual pulse cannot be treated separately. A model is needed that describes this coupled relation, which allows analyzing the closed-loop behavior of a fuel injection controller. It is also required to consider disturbed conditions in the model, which enables studying the robustness of a fuel injection controller. In this section, a single-cylinder control-oriented combustion model is introduced. Subsequently, it is validated using measurement data.

\section{A. Local combustion model}

A single-cylinder combustion model can be formulated based on the feedback control scheme discussed in Section II. Assuming that only a negligible amount of residual gas is trapped in the combustion chamber, the dependency between two consecutive combustion processes in the same cylinder is weak and has little interaction with other cylinders in the same engine. Since the diesel combustion process hardly depends on the history, it is considered static on a cycle-to-cycle basis. Hence, the control-oriented combustion model for a single cylinder can be described as

$$
x_{k}=f\left(u_{k}, v_{k}\right), z_{k}=g\left(x_{k}, v_{k}\right),
$$

where $f: \mathbb{R}^{2 m} \times \mathbb{R}^{p} \rightarrow \mathbb{R}^{n}$ describes the impact of applying different fueling profiles and $g: \mathbb{R}^{n} \times \mathbb{R}^{p} \rightarrow \mathbb{R}^{q}$ describes the relation between the combustion metrics and the engine performance. Containing both $u$ and $v$, (4) considers the interaction among individual fuel injection pulses as well as the influence of changed intake conditions. Instead of $u$, the engine performance $z$ is described as a function of the 
feedback signal $x$, which is also employed in [17]. This makes it straightforward to search for the combustion metrics setpoints $\hat{x}$ [19]. As the engine behavior is highly nonlinear, it is difficult to find the exact expression of (4) that is valid for the entire engine map. However, for small variations of $u$ and $v$, (4) can be locally represented using low-order polynomials [17].

Remark 1: The assumption of negligible amount of residual gas trapped in the combustion chamber is crucial for having the static description (4). When we have specific cam phasing or the engine valves are actively controlled, i.e. Variable Valve Actuation (VVA), it is possible to have significant amount of residual gas in the combustion chamber after every combustion process. This also influences the combustion process in addition to the fueling profile and the intake condition. As a consequence, $x_{k}$ becomes a function of $x_{k-1}, u_{k}$ and $v_{k}$.

\section{B. Model identification}

Experiments were conducted for model identification using the engine test setup CYCLOPS [20], which is a one cylinder test bench modified from a 12.6 [L] six cylinder heavy-duty engine. A Delphi DFI21 fuel injector is used in the test cylinder. The isolated exhaust gas recirculation system for the test cylinder enables accurate control of the in-cylinder condition. The engine-out gaseous emission components are measured using a Horiba MEXA system, while the smoke emission is measured using an AVL smoke meter. An uncooled AVL GU21C sensor is used to measure the pressure signal of the test cylinder. The data acquisition, real-time heat release computation and combustion metrics computation are carried out using a SpeedGoat system [21]. Commercially available diesel fuel according to EN590 specifications was used in the experiments. We chose an Euro VI type of operating condition with a pilot-main-post fuel injection profile $(m=3)$. Details about the nominal operating condition are listed in Table I. To further study the influence of deviated air-path conditions, we considered a disturbed operating condition for model identification by changing the EGR valve position from $35\left[^{\circ}\right]$ to $39\left[^{\circ}\right]$ (open). This leads to a different EGR fraction and air-fuel ratio of $34 \%$ and 1.4 , respectively. The heat release curves in both the nominal and disturbed condition are shown in Fig. 2. Due to a larger EGR fraction, the pilot combustion corresponding to the pilot injection pulse is partially suppressed in the disturbed condition.

Since (4) only contains static algebraic functions, we use steady-state measurement data for model identification. In both the nominal and the disturbed operating condition, we identify the local combustion model by locally varying the fuel injection parameters. The variation domain is listed in Table II, which is considered sufficiently large to study the local behavior. In order to capture the possible nonlinear characteristic, the variation domain of each fuel injection parameter is covered by 9 measurement points. Considering the individual variation of 6 fuel injection parameters, 49 measurement points are used for model identification. Besides individually varying each parameter, 60 measurement points with combined variations of two fuel injection parameters are

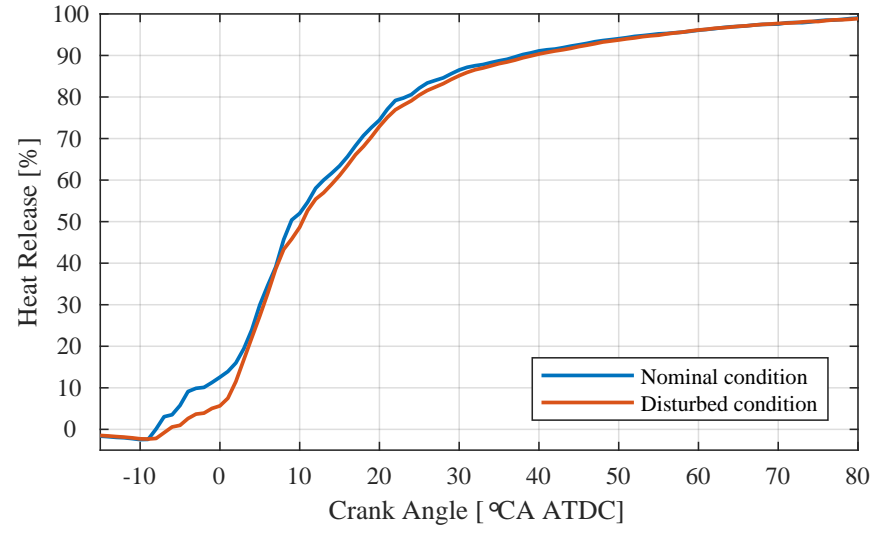

Fig. 2. Heat release comparison in the nominal and disturbed condition with changed EGR valve position.

TABLE I

NOMINAL ENGINE OPERATING CONDITION

\begin{tabular}{l|l|l|l}
\hline Engine speed & $1200[\mathrm{rpm}]$ & $\mathrm{IMEP}$ & $7.5[\mathrm{bar}]$ \\
Intake manifold pressure & $1.63[\mathrm{bar}]$ & $\mathrm{SOI}_{1}$ & $-12\left[{ }^{\circ} \mathrm{CA}\right.$ ATDC $]$ \\
Intake manifold temp. & $44\left[{ }^{\circ} \mathrm{C}\right]$ & $\mathrm{DOI}_{1}$ & $200[\mu \mathrm{s}]$ \\
Exhaust manifold pressure & $1.93[\mathrm{bar}]$ & $\mathrm{SOI}_{2}$ & $-5\left[{ }^{\circ} \mathrm{CA}\right.$ ATDC $]$ \\
Rail pressure & $1630[\mathrm{bar}]$ & $\mathrm{DOI}_{2}$ & $700[\mu \mathrm{s}]$ \\
EGR fraction & $26[\%]$ & $\mathrm{SOI}_{3}$ & $13\left[{ }^{\circ} \mathrm{CA}\right.$ ATDC $]$ \\
Air-fuel ratio $(\lambda)$ & $1.6[-]$ & $\mathrm{DOI}_{3}$ & $200[\mu \mathrm{s}]$ \\
\hline
\end{tabular}

TABLE II

VARIATION DOMAIN OF FUEL INJECTION PARAMETERS

\begin{tabular}{l|l|l|l|l}
\hline Pilot & $\mathrm{SOI}_{1}$ & $-14.5 \sim-9.5\left[{ }^{\circ} \mathrm{CA}\right.$ ATDC $]$ & $\mathrm{DOI}_{1}$ & $120 \sim 280[\mu \mathrm{s}]$ \\
Main & $\mathrm{SOI}_{2}$ & $-8 \sim-2\left[{ }^{\circ} \mathrm{CA}\right.$ ATDC $]$ & $\mathrm{DOI}_{2}$ & $600 \sim 800[\mu \mathrm{s}]$ \\
Post & $\mathrm{SOI}_{3}$ & $10 \sim 16\left[{ }^{\circ} \mathrm{CA}\right.$ ATDC $]$ & $\mathrm{DOI}_{3}$ & $120 \sim 280[\mu \mathrm{s}]$ \\
\hline
\end{tabular}

used for validation. To efficiently execute 109 measurements in both the nominal and disturbed condition, a sequence of fueling profiles is constructed, where each fuel injection parameter is changed stepwise. We apply each changed fueling profile for 25 [s], such that it takes about 45 minute to execute the whole sequence. To ensure that the steady-state measurement data is used, we compute and average the combustion metrics over the last 10 [s] for each changed fuel injection profile. Meanwhile, the cyclic variance of each metric in steady state is computed to indicate the measurement uncertainty. The considered combustion metrics include (net) IMEP, maximum cylinder pressure $\left(\mathrm{P}_{\max }\right), \mathrm{CA} 10, \mathrm{CA} 30, \mathrm{CA} 50$ and CA70, so that $n=6$. Since we modified the fuel injection profile and fixed the air-path actuations during the experiment, intake conditions are slightly deviated, e.g. varying EGR fraction $( \pm 2 \%)$ and air-fuel ratio $\lambda( \pm 0.15)$. With using slightly fewer measurement points, we carried out separate experiments to study the change of engine performance in the nominal operating condition subject to fuel injection variations. The engine performance includes the net indicated thermal efficiency $(\eta)$ and the engine-out emissions, such as NOx $\left(E_{\mathrm{NOx}}\right)$ and smoke concentration ( $\left.E_{\text {SMOKE}}\right)$.

Fig. 3 shows the relation between the combustion metrics and the variations of fuel injection parameters in both the nominal and the disturbed condition. The steady-state measurement 

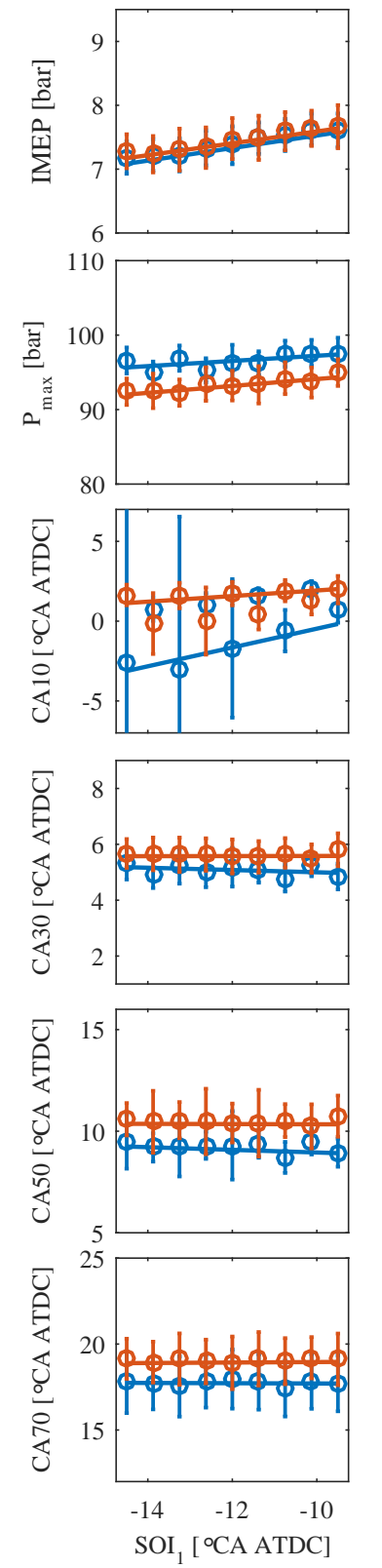
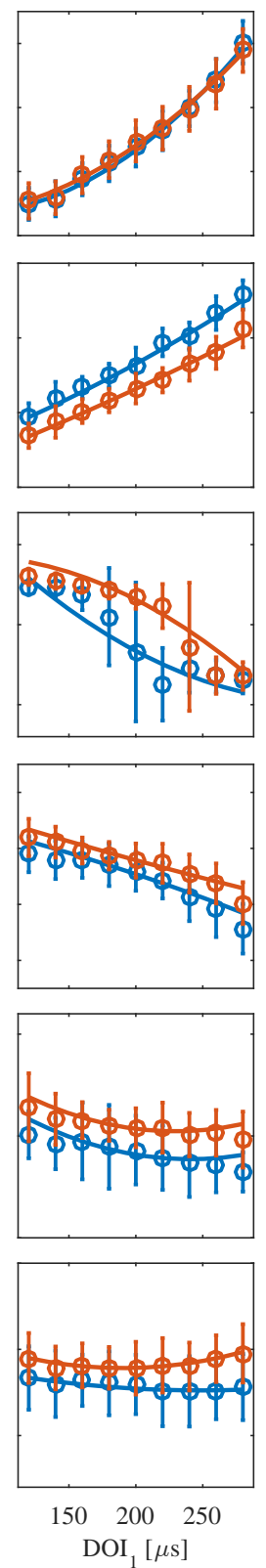
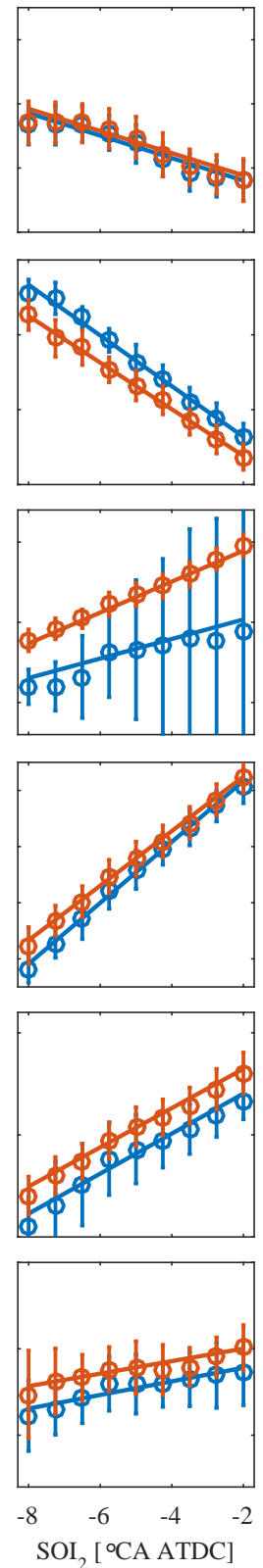
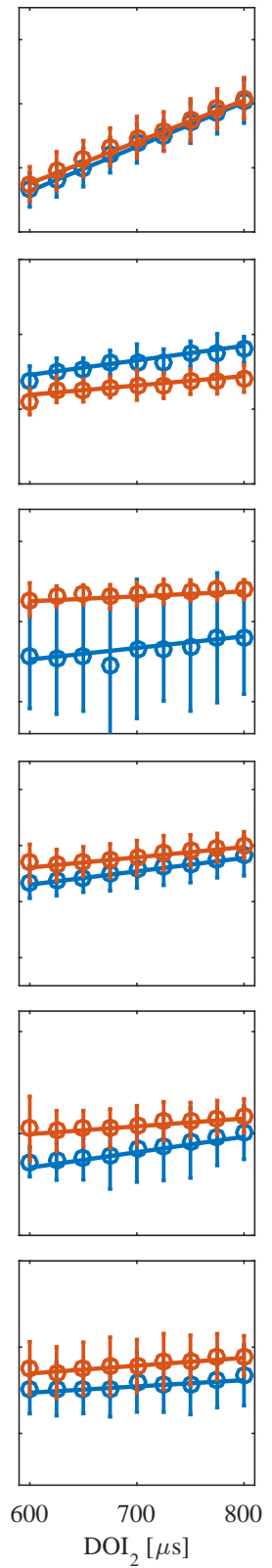
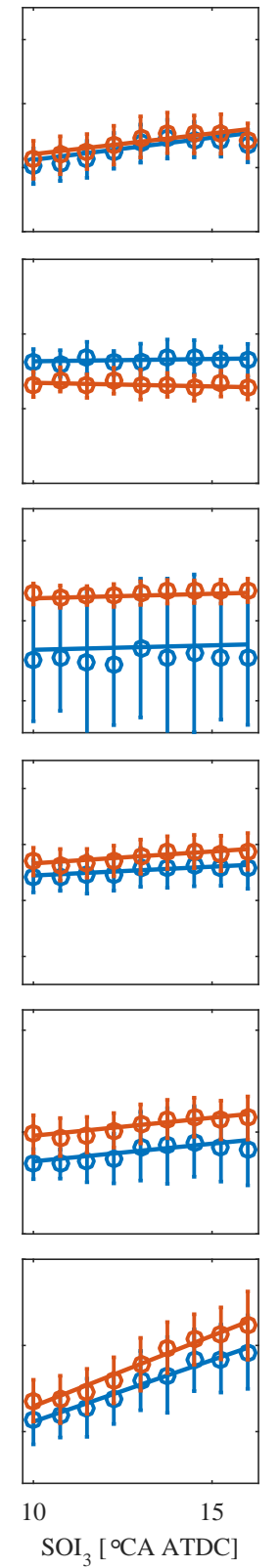
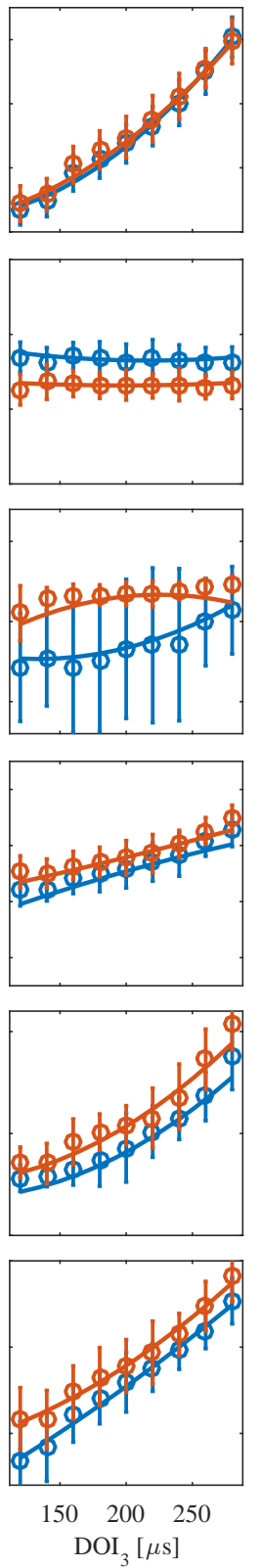

Fig. 3. Variations of the combustion metrics due to the change of each fuel injection parameter in both the nominal (blue) and the disturbed (red) operating condition. Steady-state measurement data is plotted in circles, polynomial fitting results are plotted in lines. The error bars indicate the variance $( \pm 3 \sigma)$ of each measurement point. Same horizontal scales are applied to each column of plots, and same vertical scales are applied to each row of plots.

of combustion metrics are plotted in circles, while the error bars indicate the cyclic variance $( \pm 3 \sigma)$ of each measurement point. It is clear to see that the change of each combustion metric may result from the variation of multiple fuel injection parameters. This indicates their coupled relation when having multiple fuel injection pulses. In particular, the duration of the pilot and the post injection pulse is more influential on the IMEP compared to the duration of the main injection. The main injection timing has significant influence on IMEP, which is not observed when having a single-pulse fueling profile. It can be noticed that the steady-state cyclic variance of CA10 is significantly larger than other combustion phase metrics in the nominal operating condition. This is mainly because the accumulated heat release curve becomes flat when it reaches
$10 \%$ of its maximum, as shown in Fig. 2. A small value change of the heat release curve, e.g., due to the cyclic varying incylinder pressure signal, leads to a big variation of CA10. By studying the value of $\mathrm{CA} 10$ with varying $\mathrm{DOI}_{1}$, we observe a combustion mode change, such that we do not have the pilot combustion with a short pilot injection. With a higher EGR fraction, the combustion process is retarded as shown in Fig. 2. This leads to increased combustion phase metrics and lower maximum cylinder pressure values, while IMEP is less affected. Although combustion phase metrics have different absolute values in the nominal and the disturbed condition, they preserve similar relative changes due to the variation of fuel injection parameters in both conditions. Subject to changed fuel injection parameters, the change of the engine 

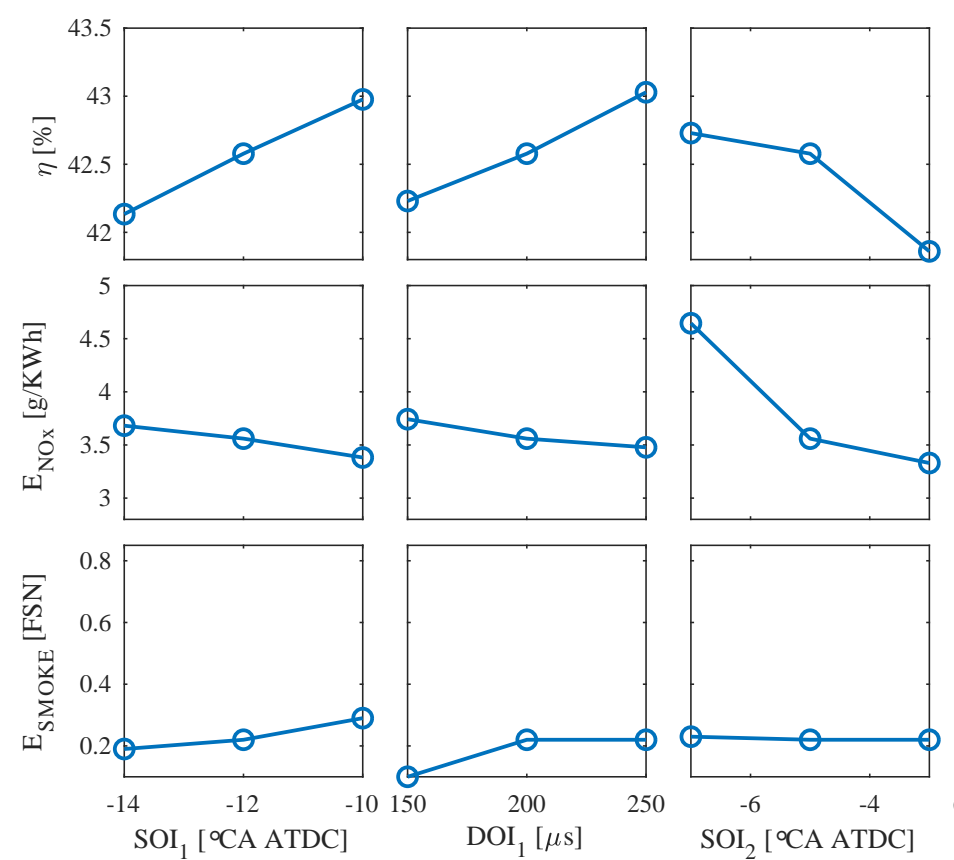

Fig. 4. Variations of the net indicated thermal efficiency and the engine-out emissions due to the change of each fuel injection parameter in the nominal operating condition as listed in Table I. Same horizontal scales are applied to each column of plots, and same vertical scales are applied to each row of plots.

performance is shown in Fig. 4. In particular, retarded main injection timing leads to lower thermal efficiency and lower NOx emission. Shorter main injection duration leads to higher NOx emission and lower smoke concentration. Longer post injection duration results in lower thermal efficiency, lower NOx emission and higher smoke concentration. Fig. 4 illustrates the need for precise fuel injection control, since a deviated fuel injection profile may lead to undesired engine performance.

As shown in Fig. 3, the combustion metrics change smoothly subject to varying fuel injection parameters, which is also observed in [17]. This indicates that the function $f$ in (4) can be locally approximated using fuel injection parameters with low order polynomials. Since we measure the engine behavior in both the nominal and the disturbed condition with different EGR valve positions, two situations are considered when fitting the measurement data. By assuming that $f$ (locally) changes affinely with varying $v$, this allows us to study the engine behavior between the considered situations, e.g., any EGR valve position between $35\left[^{\circ}\right]$ and $39\left[^{\circ}\right]$. It can be observed from Fig. 3 that combustion metrics change linearly with varying fuel injection parameters, except the pair IMEP$\mathrm{DOI}_{1}, \mathrm{CA} 10-\mathrm{DOI}_{1}, \mathrm{IMEP}_{-\mathrm{DOI}}{ }_{3}$ and CA50-DOI 3 . The second one indicates the combustion mode change, while the others reveal the nonlinearity of $f$, which is considered due to the large variation domain of $\mathrm{DOI}_{1}$ and $\mathrm{DOI}_{3}$. Hence, we fit the identification measurement data in the form of

$$
\begin{aligned}
x^{i}= & a_{0}^{i}+a_{1}^{i} \mathrm{SOI}_{1}+a_{2}^{i} \mathrm{DOI}_{1}+a_{3}^{i} \mathrm{SOI}_{2}+a_{4}^{i} \mathrm{DOI}_{2} \\
& +a_{5}^{i} \mathrm{SOI}_{3}+a_{6}^{i} \mathrm{DOI}_{3}+a_{7}^{i} \mathrm{DOI}_{1}^{2}+a_{8}^{i} \mathrm{DOI}_{3}^{2},
\end{aligned}
$$

where $x^{i}$ denotes the considered combustion metrics with $i=1 \ldots 6$. The data fitting results are listed in Table III, which includes the coefficient of determination $\left(\mathrm{R}^{2}\right)$ corresponding to the best fit (in a least-squares sense) in both the nominal
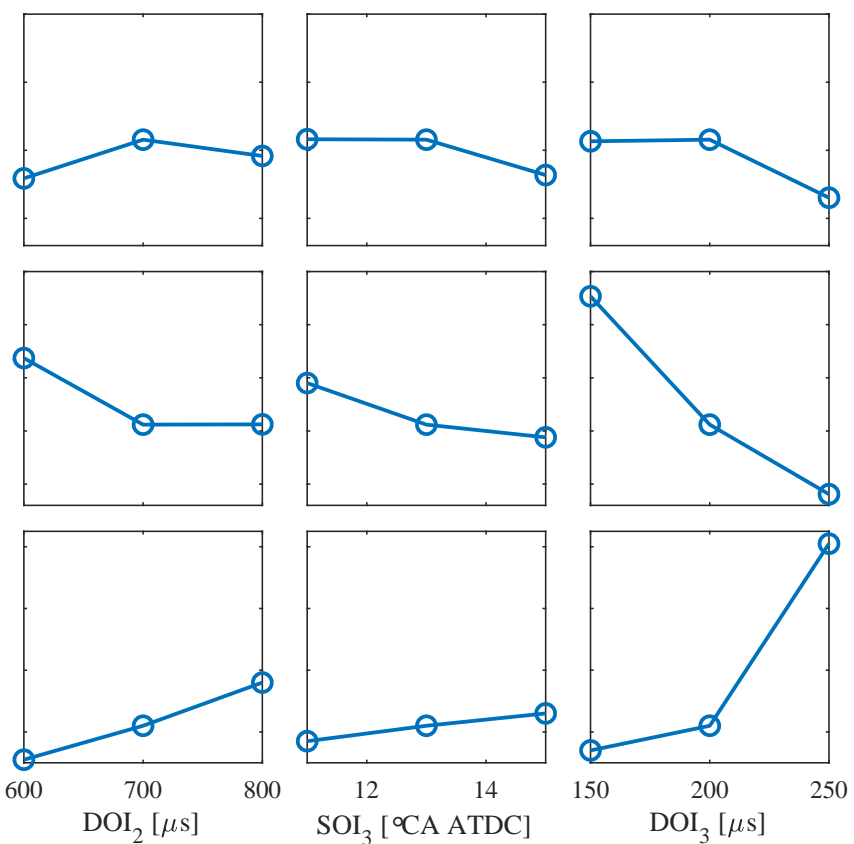

TABLE III

POLYNOMIAL FIT OF MEASURED COMBUSTION METRICS

\begin{tabular}{l|l|c|c|c|c|c|c}
\hline \multicolumn{2}{c|}{ Comb. metric } & IMEP & $P_{\max }$ & CA10 & CA30 & CA50 & CA70 \\
\hline \multirow{2}{*}{$\mathrm{R}^{2}$} & Nominal & 0.98 & 0.97 & 0.53 & 0.96 & 0.91 & 0.97 \\
& Disturbed & 0.98 & 0.98 & 0.80 & 0.97 & 0.93 & 0.97 \\
\hline \multirow{2}{*}{} & Nominal & -0.01 & 0.13 & 0.09 & -0.02 & -0.03 & 0.08 \\
& Disturbed & 0.01 & 0.06 & -0.11 & -0.01 & -0.01 & -0.01 \\
\hline
\end{tabular}

and the disturbed condition. For validation, we also include the average difference $(\epsilon)$ of those 60 validation measurement points compared to the fitting results in each condition. Judging from the high valued coefficient of determination, the data fitting quality is considered good, except for CA10 due to the combustion mode shift. The small values for $\epsilon$ indicates the high accuracy of the identified combustion model. The fitted polynomials are plotted with lines in Fig. 3. Judging from the measurement data and the fitting results, it can be concluded that the control-oriented, single-cylinder combustion model:

1) describes the coupled and nonlinear impact of varying fuel injection parameters on combustion metrics;

2) considers disturbed intake conditions.

Therefore, this model can be used to locally describe the combustion process subject to the varying multi-pulse fuel injection profile and intake conditions. This is valuable for studying the closed-loop behavior of a multi-pulse fuel injection controller.

\section{FUEL INJECTION CONTROLLER DESIGN}

The proposed control-oriented model enables us to study the closed-loop behavior of a cycle-to-cycle fuel injection controller in both the nominal and the disturbed condition. In this section, the closed-loop reference tracking dynamics is 
first studied. Afterwards, we propose a systematic approach for designing a robust and multivariable cycle-to-cycle fuel injection controller with guaranteed closed-loop stability and dynamical performance.

\section{A. Tracking error dynamics}

Following the discussion in Section II, we consider quasistatic air-path conditions when studying the closed-loop behavior of a fuel injection controller. With $v_{k}=v$ at a certain operating point, the reference tracking error for a single cylinder at step $k$ becomes

$$
e_{k}=\hat{x}-x_{k}=\hat{x}-f\left(u_{k}, v\right)
$$

As shown in Fig. 3, $f$ has a low level of nonlinearity. Via linearization, each feedback combustion signal is approximately expressed as an affine function of the fuel injection parameters. Hence, we rewrite (6) using the local gradient

$$
e_{k}=-G(v)\left(u_{k}-u^{*}\right) \text { with } G(v)=\left.\frac{\partial f(u, v)}{\partial u}\right|_{u=u^{*}},
$$

where $u^{*}$ denotes the injection parameters that results in zero tracking error, e.g., $\hat{x}=f\left(u^{*}, v\right)$, and is not necessarily equal to the fuel injection set-points $\hat{u}$. By subtracting the error signals for two sequential combustion cycles and substituting the feedback law (3), we have

$$
\begin{aligned}
e_{k+1}-e_{k} & =-G(v)\left(u_{k+1}-u_{k}\right)=-G(v)\left(u_{c, k+1}-u_{c, k}\right) \\
& =-G(v) K_{p}\left(e_{k}-e_{k-1}\right)-G(v) K_{i} e_{k} .
\end{aligned}
$$

By defining $\Delta u_{c, k} \triangleq u_{c, k+1}-u_{c, k}$ and constructing an extended vector $\varepsilon_{k}=\left[e_{k}^{\top}, e_{k-1}^{\top}\right]^{\top}$ with $e_{-1}=e_{0}$ by assumption, we can rewrite (8) into the closed-loop error dynamics

$$
\begin{gathered}
\varepsilon_{k+1}=A \varepsilon_{k}+B(v) \Delta u_{c, k}, \Delta u_{c, k}=K \varepsilon_{k}, \text { with } \\
A=\left[\begin{array}{ll}
I & 0 \\
I & 0
\end{array}\right], B(v)=\left[\begin{array}{c}
-G(v) \\
0
\end{array}\right], K=\left[K_{p}+K_{i}-K_{p}\right] .
\end{gathered}
$$

Based on the definition of the reference tracking error, we know that the reference combustion metrics $\hat{x}$ is met when $\varepsilon_{k}$ becomes zero. Hence, the objective in designing a cycleto-cycle fuel injection controller is to find a $K$, such that $\varepsilon_{k}$ converges to zero exponentially. According to [22, p. 71], we define local exponential stability in discrete-time domain as

$$
\left\|\varepsilon_{k}\right\|^{2} \leqslant \beta \alpha^{k}\left\|\varepsilon_{0}\right\|^{2}
$$

where $\alpha \in[0,1)$ and $\beta \in \mathbb{R}_{>0}$ and any $\varepsilon_{0}$ near the origin. The system (9) is locally exponentially stable for a given $K$ at the equilibrium, if there exists a quadratic Lyapunov function of the form $V(\varepsilon)=\varepsilon^{\top} P \varepsilon$ for a symmetric and positive definite matrix $P^{\top}=P \succ 0$ with $P \in \mathbb{R}^{2 n \times 2 n}$, such that

$$
(A+B(v) K)^{\top} P(A+B(v) K) \preceq \alpha P, \alpha \in[0,1) .
$$

For a given $K,(11)$ is a Linear Matrix Inequality (LMI), which can be used to verify the closed-loop stability of (9). Based on the definition of the Lyapunov function, (11) indicates that $V\left(\varepsilon_{k+1}\right) \leqslant \alpha V\left(\varepsilon_{k}\right)$. By defining $\lambda_{\max }(P)$ and $\lambda_{\min }(P)$ as the maximum and minimum eigenvalue of $P$, respectively, we know $\lambda_{\min }(P)\|\varepsilon\|^{2} \leqslant \varepsilon^{\top} P \varepsilon \leqslant \lambda_{\max }(P)\|\varepsilon\|^{2}$. Hence, we demonstrate the exponential stability by showing

$$
\lambda_{\text {min }}(P)\left\|\varepsilon_{k}\right\|^{2} \leqslant V\left(\varepsilon_{k}\right) \leqslant \alpha^{k} V\left(\varepsilon_{0}\right) \leqslant \lambda_{\max }(P) \alpha^{k}\left\|\varepsilon_{0}\right\|^{2} .
$$

This leads to $\beta=\lambda_{\max }(P) / \lambda_{\min }(P)$ as in (10). We can test the stability of a given fuel injection controller by verifying the feasibility of (11). Since the choice of $K$ is not restricted in (9), this method of stability verification applies to both parallel and multivariable fuel injection controllers, e.g., [4], [9]-[12].

To evaluate the controller's dynamical performance, we define the settling time $T$ as the number of combustion cycles it takes to achieve and remain $\pm 2 \%$ of the error signal $\left(\left\|\varepsilon_{k}\right\|^{2} \leqslant 0.02\left\|\varepsilon_{0}\right\|^{2}\right)$, and is conservatively upper limited by

$$
T \leqslant\left\lceil\log _{\alpha}\left(\frac{0.02}{\beta}\right)\right\rceil,
$$

where $[\cdot]$ means rounding up towards the larger integer. For constant $\beta$, a controller has a (guaranteed) faster convergence rate and a shorter settling time with smaller $\alpha$. As shown in Section III-B, the change of multi-pulse fuel injection parameters has coupled impact on the combustion metrics. The adoption of a decoupled control scheme limits the dynamical performance as it imposes an additional constraint on the controller structure. Furthermore, it is difficult to find the optimal pairing between the controlled fuel injection parameters and feedback combustion metrics when having multiple fuel injection pulses. Hence, a multivariable fuel injection controller is preferred.

Remark 2: To ensure that (9) is controllable, the matrix $G(v)$ needs to be square and full rank. This condition is usually met when there is only a single fuel injection pulse and IMEP and CA50 are used as feedback signals. With multiple fuel injection pulses, more feedback signals are needed for controlling an increased number of injection parameters. However, it is difficult to preserve a full rank $G(v)$ by including more combustion phasing metrics as the feedback signals, since their changes due to varying fueling profiles are linearly dependent. This limits the maximum number of controlled fuel injection parameters, which indicates the fundamental difficulty of the control problem and motivates the usage of alternative feedback signals.

\section{B. Systematic controller design approach}

Based on the LMI condition for stability given by (11), it is possible to manually tune a stable fuel injection controller that satisfies certain performance requirements. With additional attempts, this can be even done for multiple operating points or disturbed conditions. To achieve higher efficiency in designing a fuel injection controller, we automate the design process by proposing a systematic approach, which computes a multivariable controller with guaranteed robust stability and dynamical performance.

As $G(v)$ depends on the operating conditions, the matrix $B(v)$ in (9) varies according to disturbances. We consider the set $B_{\Delta}=\left\{B_{1}, B_{2}, \ldots, B_{s}\right\}$ that represents the variation of the combustion behavior for $s \in \mathbb{N}$ severally disturbed conditions. In addition, we assume that the engine behavior $B$ in any 
disturbed condition can be expressed as a linear combination of the elements in $B_{\Delta}$, such that $B \in \operatorname{Conv}\left\{B_{\Delta}\right\}$. With reduced implementation effort, it is desired to design a single fuel injection controller that is stabilizing in multiple situations with satisfying dynamical performance. Hence, $\operatorname{Conv}\left(B_{\Delta}\right)$ is considered as the model uncertainty in the controller design procedure. With larger flexibility due to less structural restrictions, a multivariable fuel injection controller is preferred over a parallel one to cope with different situations.

Applying Schur complement, we can transform the stability analysis LMI (11) into a controller synthesis LMI. By preand post-multiplying $\operatorname{diag}(Z, I)$ and considering $B_{i} \in B_{\Delta}$, we have

$$
\left[\begin{array}{cc}
\alpha Z & Z A^{\top}+Y^{\top} B_{i}^{\top} \\
A Z+B_{i} Y & Z
\end{array}\right] \succeq 0,
$$

where $Y=K P^{-1}$ and $Z=P^{-1}$. The error dynamics (9) is robustly stable with the (given) convergence upper bound $\alpha$ in the set $B_{\Delta}$, if there exists a matrix $Y$ and a symmetric positive definitive matrix $Z$, such that (13) is feasible for all $B_{i} \in B_{\Delta}$. Both $Y$ and $Z$ can be computed numerically using semidefinite programming, e.g., using YALMIP/SeDuMi [23]. If (13) is feasible, the controller is given by $K=Y Z^{-1}$, so that $K_{p}$ and $K_{i}$ can be computed according to (9). Using a common Lyapunov function, i.e., $Z$ does not depend on $i$, the designed fuel injection controller becomes robustly stable for the model uncertainty $\operatorname{Conv}\left(B_{\Delta}\right)$ such that (9) is stable subject to any considered disturbances. Since no structural constraint is applied, the computed controller is multivariable. Dominantly influencing the settling time as pointed out by (12), $\alpha$ is considered as a design parameter, which imposes requirements on controller's dynamical performance.

Remark 3: We have limited flexibility in shaping the multipulse fueling profile due to injector's limitation, i.e., minimal injection duration and minimal dwell time between two consecutive injection pulses. This is considered as constraints of the fuel injection parameters. Instead of considering these constraints in the controller design process, saturations of the controller outputs can be implemented to ensure safe operation. However, we believe that reasonably chosen reference signals are of great importance to avoid violating injector's capability. For example, the reference CA30 should be less than CA50 since the heat release curve is a monotonically increasing function and the rate of heat release is bounded.

\section{EXPERIMENTAL RESULTS}

Following the proposed systematic approach, we design a multivariable fuel injection controller and test its robust stability and disturbance rejection capability using the same engine test bench as described in Section III-B. In this section, we first present the controller design procedure. Then, the experimental results are presented and discussed.

\section{A. Controller design}

We design the cycle-to-cycle fuel injection controller based on the fitted control-oriented combustion model that is discussed in Section III-B. With $m=3$ injection pulses, the matrix $G$ in (9) has the dimension of $6 \times 6$ according to the local linearization. However, $G$ is not full rank since some singular values are too small to be considered significant. This indicates that the closed-loop dynamics is uncontrollable according to Remark 2. To ensure the controllability, $G$ needs to be downsized by reducing the number of controlled fuel injection parameters and feedback combustion metrics. Since the change of $\mathrm{SOI}_{1}$ does not have significant influence on feedback metrics, it is not closed-loop controlled. $\mathrm{P}_{\max }$ is not considered as the feedback signal as it is linearly dependent on the other phase metrics. Moreover, the limited number of suitable feedback combustion metrics further reduces the number of controlled fuel injection parameters. As shown in Fig. 3, CA10 has very large steady-state variance in the nominal operating condition and is significantly affected by the combustion mode change. This excludes the feasibility of using CA10 as the feedback signal for closed-loop combustion control. Similarly, CA70 is also not considered for feedback due to its large steady-state variance. Consequently, $\mathrm{DOI}_{1}$ and $\mathrm{SOI}_{3}$ are not closed-loop controlled since their variations mainly influence the combustion phase with CA10 and CA70, respectively. Hence, the input and feedback signals selected for closed-loop combustion control are as follows:

$$
u=\left[\mathrm{SOI}_{2}, \mathrm{DOI}_{2}, \mathrm{DOI}_{3}\right]^{\top}, x=[\mathrm{IMEP}, \mathrm{CA} 30, \mathrm{CA} 50]^{\top} .
$$

The control problem is considered complex with three closedloop controlled fuel injection parameters and three feedback combustion metrics, which is difficult to handle using a parallel controller. As shown in Fig. 4, the variation of the main injection timing, main injection duration and post injection duration has significant influence on the indicated thermal efficiency, engine-out NOx and smoke concentration. The selected feedback combustion metrics allow us to closedloop control the fuel injection parameters, which effectively influence the engine performance indicators.

Based on the selection of controlled fuel injection parameters and feedback combustion metrics, we describe the reference tracking dynamics by following the derivation in Section IV-A. Considering both the nominal and disturbed operating conditions as discussed in Section III-B, we have two considered situations for $B_{\Delta}$, with

$$
\begin{aligned}
B_{1}= & {\left[\begin{array}{cccccc}
0.1751 & -1.0861 & -0.9806 & 0 & 0 & 0 \\
-0.2765 & -0.1907 & -0.3037 & 0 & 0 & 0 \\
-0.6505 & -0.5334 & -1.4042 & 0 & 0 & 0
\end{array}\right]^{\top}, } \\
B_{2}= & {\left[\begin{array}{cccccc}
0.1728 & -0.9730 & -0.9612 & 0 & 0 & 0 \\
-0.2592 & -0.1467 & -0.1535 & 0 & 0 & 0 \\
-0.6232 & -0.4650 & -1.5861 & 0 & 0 & 0
\end{array}\right]^{\top}, }
\end{aligned}
$$

Described in different units, both input and feedback signals are normalized, so that the entries of $B_{1}$ and $B_{2}$ are of similar magnitudes. Following the systematic approach discussed in Section IV-B, a multivariable fuel injection controller is designed by solving (13) with $\alpha=0.6$, which leads to fast dynamical performance according to (12). The resulting 

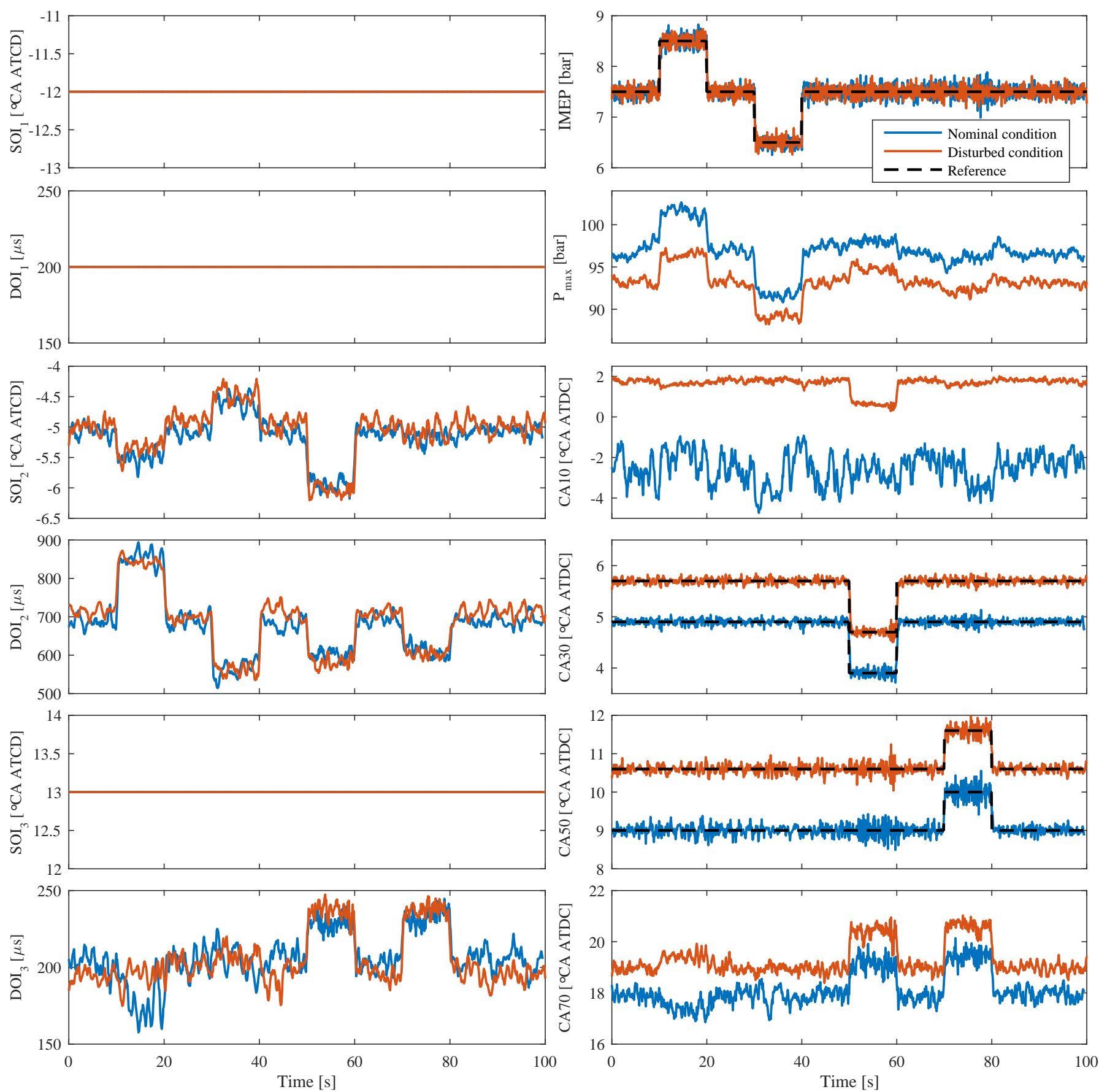

Fig. 5. Reference tracking test in both the nominal and the disturbed operating condition.

controller is

$$
\begin{aligned}
K_{p} & =\left[\begin{array}{ccc}
-0.0100 & 0.0182 & -0.0087 \\
0.1159 & 0.0998 & -0.0981 \\
-0.0144 & -0.0330 & 0.0265
\end{array}\right], \\
K_{i} & =\left[\begin{array}{ccc}
-0.4920 & 0.7782 & 0.0013 \\
2.2290 & 1.8008 & -1.4878 \\
0.0373 & -0.7060 & 0.8238
\end{array}\right] .
\end{aligned}
$$

With larger entry values, $K_{i}$ is more influential on the reference tracking dynamics compared to $K_{p}$. Compared to CA50, the tracking error of CA30 has a larger influence on $\mathrm{SOI}_{2}$.
Compared to $\mathrm{DOI}_{3}, \mathrm{DOI}_{2}$ is more sensitive to the tracking error of IMEP. Both $\mathrm{DOI}_{2}$ and $\mathrm{DOI}_{3}$ react on the tracking error of CA30 and CA50, which illustrates coupled feedback loops. With $\beta=10.5$, the estimated upper limit of the settling time is 13 combustion cycles according to (12).

\section{B. Results}

1) Reference tracking: The designed controller's robust stability and dynamical performance are tested in both the nominal and the disturbed operating condition, which are discussed in Section III-B. We design challenging reference 

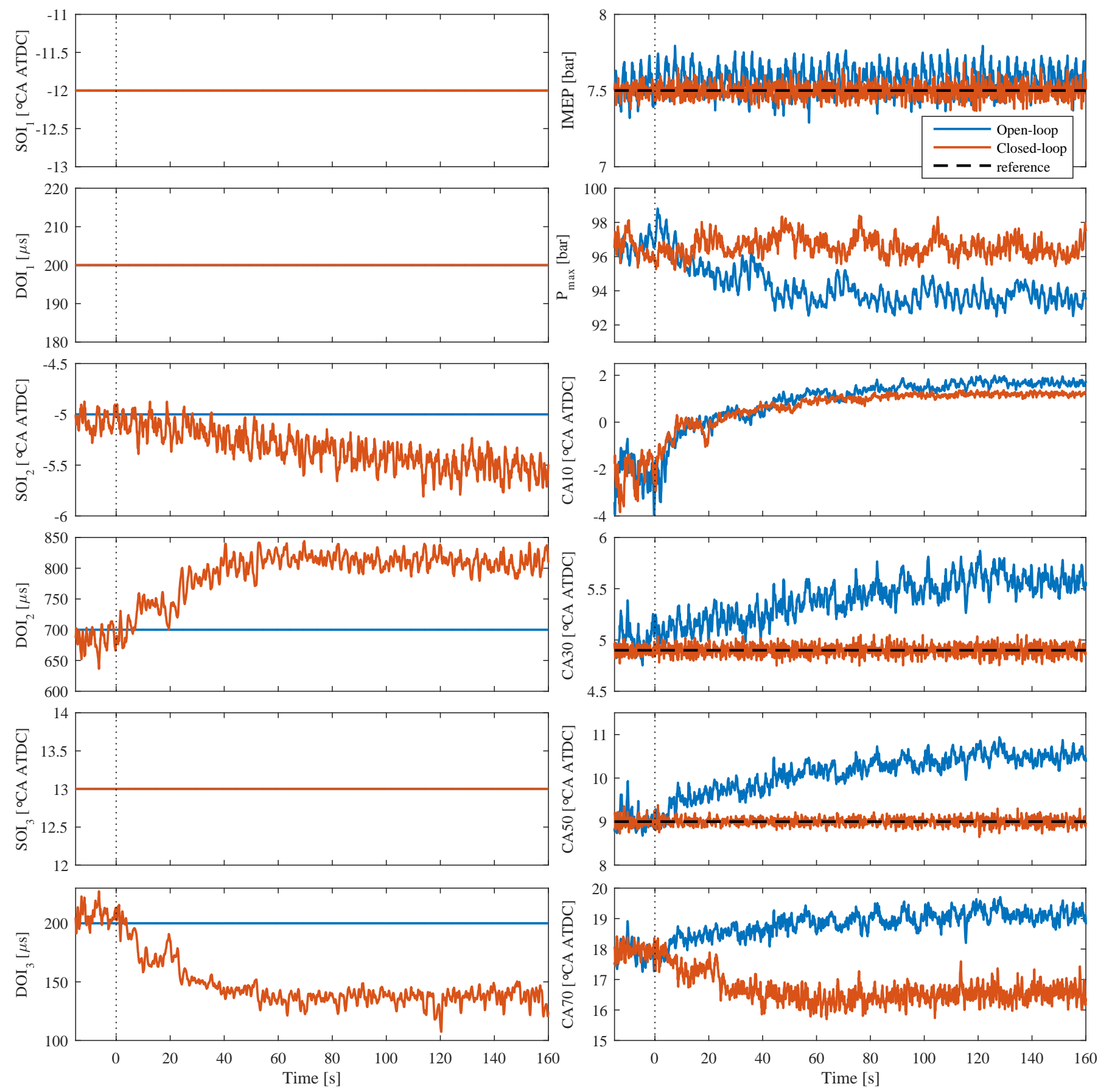

Fig. 6. Disturbance rejection test subject to a step change of the EGR valve position, which increases the EGR ratio by $8 \%$.

signals for controlled feedback combustion metrics in each operating condition. The reference value for IMEP is first changed in steps with 1 [bar]. This is followed by step-wise changes of reference CA30 and CA50 with $1\left[{ }^{\circ} \mathrm{CA}\right]$. Since the maximum rate of heat release happens between CA30 and CA50, it is difficult to further reduce the difference in between. Hence we only advance CA30 and retard CA50 by $1\left[{ }^{\circ} \mathrm{CA}\right]$ when designing the tracking reference.

Fig. 5 shows the reference tracking test in both the nominal and the disturbed operating condition. The measurement signals are off-line processed by Savitzky-Golay filters to reduce the cyclic noise level. The controller manipulates the controlled fuel injection parameters $\left(\mathrm{SOI}_{2}, \mathrm{DOI}_{2}\right.$ and $\left.\mathrm{DOI}_{3}\right)$ to track the reference changes in IMEP, CA30 and CA50, while the uncontrolled injection parameters $\left(\mathrm{SOI}_{1}, \mathrm{DOI}_{1}\right.$ and $\mathrm{SOI}_{3}$ ) remain unchanged. Not being closed-loop controlled, $\mathrm{P}_{\max }, \mathrm{CA} 10$ and CA70 vary according to the changing fueling profile. The results illustrate the controller's robust stability since it manages to track the reference in both conditions. Due to the coupled relation, multiple injection parameters need to be changed to track the change of one feedback combustion metric. Both $\mathrm{SOI}_{2}$ and $\mathrm{DOI}_{2}$ are changed to track the step 
change in IMEP while keeping CA30 and CA50 unchanged. To reduce CA30, the controller advances the main injection timing. Meanwhile, the main and the post injection duration are changed to maintain the same value for IMEP and CA50. Without changing $\mathrm{SOI}_{2}$, the controller manipulates $\mathrm{DOI}_{2}$ and $\mathrm{DOI}_{3}$ to increase CA50 with unchanged IMEP and CA30. Besides robust stability, the dynamical performance of the controller is also considered satisfactory since it tracks the step reference changes quickly without significant overshoots. Judging from the testing results, the settling time is considered as 5 combustion cycles, which equals 0.5 [s] and is lower than the estimated upper limit (13 combustion cycles). We study the cyclic combustion variance with open-loop and closed-loop combustion control by comparing the steady-state variance of IMEP over 50 combustion cycles. In comparison with the open-loop case, the steady-state variance of closed-loop controlled IMEP changes insignificantly, as it reduces by $7 \%$ and increases by $2 \%$ in the nominal and disturbed operating condition, respectively. Hence, the cyclic combustion variance is not considerably affected by the closed-loop controller.

2) Disturbance rejection: Besides the controller's robust stability, we also investigated its capability of rejecting the air-path disturbances. The considered disturbance is applied by changing the EGR valve position from $35\left[^{\circ}\right]$ to $39\left[^{\circ}\right]$ (open), which increases the EGR ratio by $8 \%$. The experimental results are shown in Fig. 6, where the feedback combustion metrics are again off-line processed by Savitzky-Golay filters to reduce the cyclic noise level. Starting with the nominal operating condition, the EGR valve position is manipulated at time equals zero. With open-loop combustion control, the fueling profile remains unchanged, while the combustion metrics drift from their initial values due to disturbed intake conditions. Since a mixing tank is used to better blend the exhaust gas with fresh air, the transient response subject to the change of EGR valve position is slower than production engines. With closed-loop fuel injection control, fuel injection parameters $\left(\mathrm{SOI}_{2}, \mathrm{DOI}_{2}\right.$ and $\left.\mathrm{DOI}_{3}\right)$ are manipulated, so that the values of the feedback combustion metrics (IMEP, CA30, CA50) are maintained subject to disturbed EGR valve position. The experimental results verify that the designed controller remains stable during the transient between the nominal and the disturbed operating condition, which is guaranteed in the design procedure.

\section{Conclusions}

In this paper, we have presented a general framework for cycle-to-cycle fuel injection control for advanced diesel combustion with multi-pulse fuel injection. A single-cylinder, control-oriented combustion model has been introduced and validated using experimental data. The model explicitly considers disturbed intake conditions as well as the coupled effect of the multiple fuel injection pulses on the combustion process. Using this model, we are able to analyze the closed-loop reference tracking dynamics of a cycle-to-cycle fuel injection controller. A systematic design approach has been introduced that computes a multivariable fuel injection controller with guaranteed robust stability and dynamical performance. Following the design approach, we experimentally demonstrated the resulting controller's robust reference tracking performance and fast settling time ( 0.5 [s] / 5 combustion cycles). The controller's capability of disturbance rejection is also illustrated subject to increased EGR ratio by $8 \%$. Since the multipulse fueling profile has a nonlinear impact on the combustion process and may change the combustion mode, it is of further interest to consider this in future work. Future work also includes testing a cycle-to-cycle fuel injection control in speed/torque transients and studying its contribution to the engine performance.

\section{ACKNOWLEDGMENTS}

This work is part of the research programme "Heat2Control: In-cycle control for low $\mathrm{CO} 2$ combustion concepts" with project number 12678 , which is partly financed by the Netherlands Organisation for Scientific Research (NWO). The authors would like to thank Sivasubramanian Velayutham for his support on realizing the control system, and Shuli Wang and Robbert Willems for giving instructions on operating the engine test setup.

\section{REFERENCES}

[1] R. Ehleskog, R. Ochoterena, and S. Andersson, "Effects of multiple injections on engine-out emission levels including particulate mass from an HSDI diesel engine," SAE Technical Paper, 2007-01-0910.

[2] A. Dempsey, N. Walker, E. Gingrich, and R. Reitz, "Comparison of low temperature combustion strategies for advanced compression ignition engines with a focus on controllability," Combustion Science and Technology, vol. 186, no. 2, pp. 210-241, 2014.

[3] O. Özener, L. Yüksek, A. T. Ergenç, and M. Özkan, "Effects of soybean biodiesel on a DI diesel engine performance, emission and combustion characteristics," Fuel, vol. 115, pp. 875-883, 2014.

[4] F. Willems, E. Doosje, F. Engels, and X. Seykens, "Cylinder pressurebased control in heavy-duty EGR diesel engines using a virtual heat release and emission sensor," SAE Technical Paper, 2010-01-0564.

[5] T. Miyaura, A. Morikawa, Y. Ito, K. Ishizuka, and T. Tsuiki, "Development of diesel engine using new fuel injection system - direct monitoring of fuel injection pressure using injector with built-in sensor, and its applications," SAE Technical Paper, 2013-01-1739.

[6] P. Ortner and L. del Re, "Predictive control of a diesel engine air path," IEEE Transactions on Control Systems Technology, vol. 15, no. 3, pp. 449-456, 2007.

[7] J. Hadler, F. Rudolph, R. Dorenkamp, H. Stehr, J. Hilzendeger, and S. Kranzusch, "Volkswagen's new 2.0 1 TDI engine for the most stringent emission standards - part 1," MTZ worldwide, vol. 69, no. 5, pp. 12-18, 2008.

[8] D. Selmanaj, H. Waschl, M. Schinnerl, S. Savaresi, and L. del Re, "Dynamic injection adaptation by input shaping for low NOx emissions during transients," SAE Technical Paper, 2014-01-1161.

[9] I. Haskara and Y. Wang, "Cylinder pressure-based combustion controls for advanced diesel combustion with multiple-pulse fuel injection," IEEE Transactions on Control Systems Technology, vol. 21, no. 6, pp. 2143$2155,2013$.

[10] S. Yu, H. Choi, S. Cho, K. Han, and K. Min, "Development of engine control using the in-cylinder pressure signal in a high speed direct injection diesel engine," International Journal of Automotive Technology, vol. 14 , no. 2 , pp. 175-182, 2013.

[11] R. Saracino, M. Gaballo, S. Mannal, S. Motz, A. Carlucci, and M. Benegiamo, "Cylinder pressure-based closed loop combustion control: A valid support to fulfill current and future requirements of diesel powertrain systems," SAE Technical Paper, 2015-24-2423.

[12] X. Luo, S. Wang, B. de Jager, and F. Willems, "Cylinder pressurebased combustion control with multi-pulse fuel injection," IFACPapersOnLine, vol. 48, no. 15, pp. 181-186, 2015.

[13] M. Karlsson, K. Ekholm, P. Strandh, R. Johansson, and P. Tunestal, "Multiple-input multiple-output model predictive control of a diesel engine," 6th IFAC Symposium Advances in Automotive Control, pp. 131$136,2010$. 
[14] W. Glewen, D. Heuwetter, D. Foster, M. Andrie, and R. Krieger "Analysis of deviations from steady state performance during transient operation of a light duty diesel engine," SAE Int. J. Engines, vol. 5, pp. 909-922, 2012.

[15] J. Hinkelbein, C. Sandikcioglu, S. Pischinger, M. Lamping, and T. Körfer, "Control of the diesel combustion process via advanced closed loop combustion control and a flexible injection rate shaping tool," $S A E$ Technical Paper, 2009-24-0114.

[16] F. Tschanz, A. Amstutz, C. Onder, and L. Guzzella, "Feedback control of particulate matter and nitrogen oxide emissions in diesel engines," Control Engineering Practice, vol. 21, no. 12, pp. 1809-1820, 2013.

[17] M. Hillion, H. Buhlbuck, J. Chauvin, and N. Petit, "Combustion control of diesel engines using injection timing," SAE Technical Paper, 200904-20.

[18] G. F. Franklin, J. D. Powell, and M. L. Workman, Digital Control of Dynamic Systems. Addison-Wesley, 1997.

[19] M. Lewander, A. Widd, B. Johansson, and P. Tunestål, "Steady state fuel consumption optimization through feedback control of estimated cylinder individual efficiency," in American Control Conference (ACC), 2012, pp. 4210-4214.

[20] S. Wang, P. C. Bakker, L. M. T. Somers, and L. P. H. de Goey, "Effect of air-excess on blends of RON70 partially premixed combustion," Flow, Turbulence and Combustion, vol. 96, no. 2, pp. 309-326, 2016.

[21] S. Kulah, A. Forrai, F. Rentmeester, T. Donkers, and F. Willems, "Robust cylinder pressure estimation in heavy-duty diesel engines," International Journal of Engine Research, vol. 19, no. 2, pp. 179 - 188, 2017.

[22] J. P. Hespanha, Linear Systems Theory. Princeton University Press, 2009.

[23] J. Löfberg, "YALMIP : a toolbox for modeling and optimization in MATLAB," in IEEE International Conference on Robotics and Automation, 2004, pp. 284-289. 